
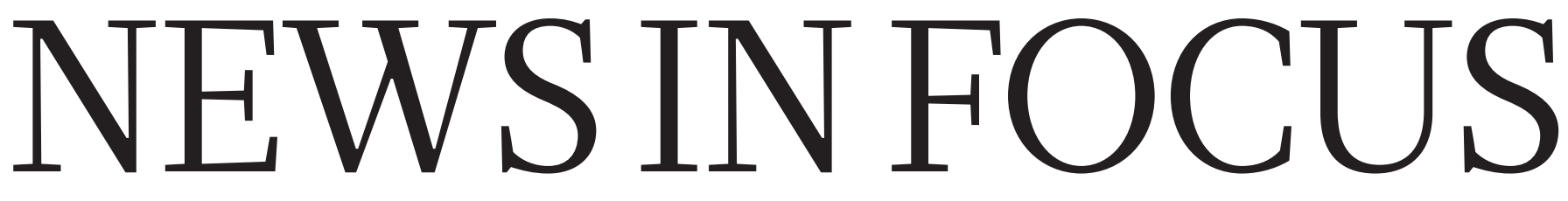

SUSTAINABILITY Scientists call for sharper focus in UN antipoverty push $\mathbf{p . 4 3 4}$
BRAIN STIMULATION Studies in children raise hopes and fears for the technology $\mathbf{p . 4 3 6}$
ASTROSAT Indian space observatory excites astronomers globally p.438

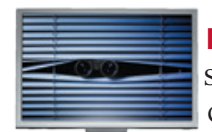

PRIVACY Researchers seek safe ways to mine confidential data $\mathbf{p . 4 4 0}$

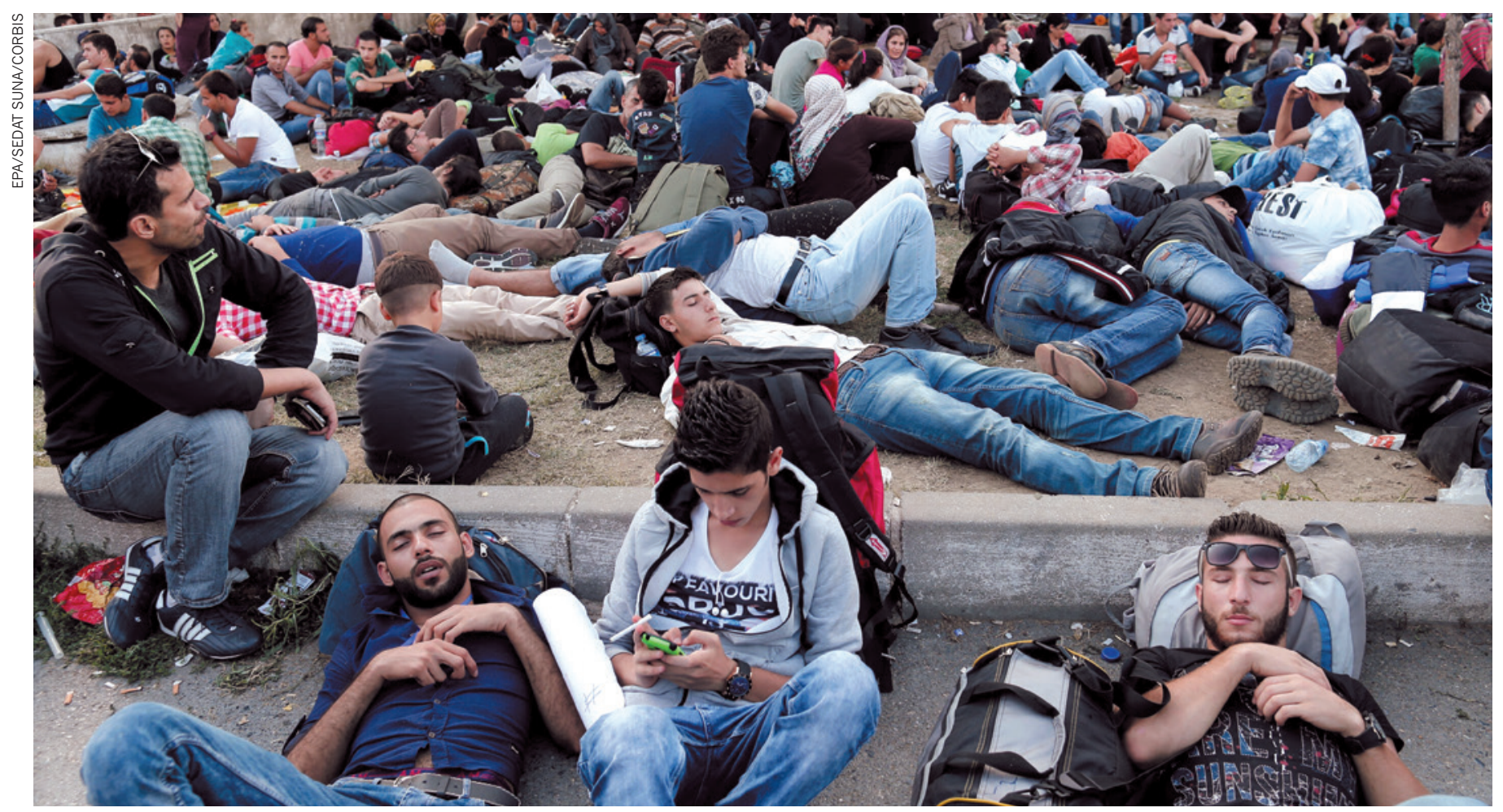

Syrian refugees wait for a bus in Istanbul, Turkey: many young people are missing out on higher education as a result of conflict in the Middle East.

\title{
MIDDLE EAST
}

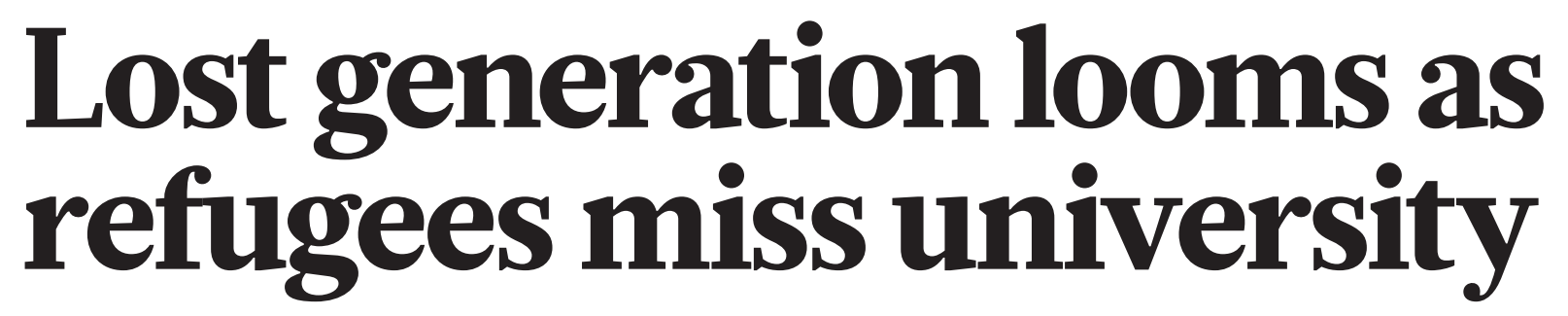

Educational void risks hampering reconstruction in Middle East.

\section{BY DECLAN BUTLER}

$\mathrm{H}$ uman-rights organizations are calling on universities and governments worldwide to invest more in the education of the hundreds of thousands of student refugees who are fleeing war-torn regions of the Middle East.

They warn that the countries in conflict risk losing a future generation of scientists, engineers, physicians, teachers and leaders and that university-aged refugees who have found shelter elsewhere represent a crucial opportunity to reverse some of the lost intellectual capital. "Each scholar and student that we lose now deepens the challenge of restoring the region when the violence eventually subsides," says Robert Quinn, executive director of the Scholars at Risk Network, a human-rights group headquartered in New York City.

Quinn also cautions that allowing an educational void to develop in the Middle East could create a fertile recruiting environment for radical militias and terrorists. "It is deeply in the interest of Europe and the West to protect and invest in the intellectual capital of the region," he says. "The failure to invest massively is foolishly shortsighted."

Conflicts in Syria, Iraq and Yemen, as well as in Libya and other North African countries, have led to a record number of refugees. By the end of 2014, 60 million people worldwide were seeking refuge either in safer parts of their countries or abroad, according to the Office of the United Nations High Commissioner for Refugees. That is the highest number ever recorded, and almost double the 37.5 million displaced individuals a decade earlier.

Syria, which had a population of nearly 
- 21 million before the ongoing conflict there began four years ago, has produced the most refugees, with 7.6 million people displaced internally and a further 4 million forced to flee the country. Around 10\% of those people are of university age, estimates James King, who is a senior researcher at the Scholar Rescue Fund, part of the Institute of International Education (IIE), a non-profit, educational-exchange organization in New York City.

Yet the university system in Syria has all but collapsed, and few of the young people who have left the country are receiving higher education. Of those refugees who fled abroad, most have found temporary shelter in neighbouring countries - Turkey is hosting some 1.8 million, Lebanon 1.2 million and Jordan 630,000 - but only around $5 \%$ of the university-aged refugees in these countries are enrolled at local institutions, according to a March report funded by the European Commission (see go.nature.com/9ljpbl).

Before the conflict began, $26 \%$ of young adults in Syria were receiving tertiary education. That leaves hundreds of thousands of people who would normally be attending university going without.

Even when universities in the refugees' host countries have capacity - and this in itself is an issue; Turkey, for example, is struggling to accommodate all of its own eligible and interested students - there are a string of further impediments to enrolment. Many students have fled without documents, says King, including records of past academic credentials. Other issues are financial and material hardships, which can force young adults to work, leaving them no time for education. In Turkey, where just $1 \%$ of Syrian refugees aged 18-24 have found university places, language

difficulties are a big problem.

Scholarships are available. The IIE-led Syria Consortium for Higher Education in Crisis, a network of higher-education institutions worldwide that was created in 2012, has provided US $\$ 4.5$ million to support 333 Syrian students, including 158 scholarships to attend universities in Western countries. At least 20 similar initiatives also offer scholarships to institutions across the globe. However, demand far outstrips supply: these combined efforts have been able to provide only around 7,000 students with

\section{"Education is some form of tertiary} the orphan of all these crises.

People are so

concerned about

food, water,

shelter and

other basics." education.

Allan Goodman, president and chief executive of the IIE, notes the sheer scale of the crisis. "No organization or country is set up to deal with it," he says, "The only thing we can do is - one by one, family by family, scholar by scholar, student by student - try to help individuals."

He also says that humanitarian efforts have tended to focus on saving lives and relieving misery among those fleeing conflict. "Education is the orphan of all these crises," he says. "People are so concerned about food, water, shelter and other basics, and we haven't thought enough about education." The 1.5\% of global humanitarian aid that goes to education, meanwhile, is spent largely on primary and secondary schooling, not higher education, which traditionally has been seen as a luxury.

There are signs that attitudes are changing. In May, the European Union's trust fund for the Syrian crisis committed $€ 12$ million (US\$14.5 million) to assist 20,000 Syrian refugees in obtaining higher education through scholarships and other means. As the European Commission report notes, however, scholarships cannot meet the enormous need, which would amount to billions, not millions, of euros.

It would be more cost effective to provide direct financial aid to universities in the countries with the most Syrian refugees, the report states. And various organizations, including the UN children's charity, UNICEF, are exploring whether the massive open online courses (MOOCs) now offered by some top universities could also help. By using recorded lectures and social-networking-style communication, for example, MOOCs are intended to democratize access to a world-class education. But they are largely untested in a refugee situation, Goodman says, and most students still want a diploma accredited by a ministry of education. "A MOOC from Stanford or MIT isn't the same," he says. "The most durable situations are those that seek to integrate students into national university systems."

Clearly, a long-term solution will require enormous investment and much greater involvement by higher-education institutions worldwide, Quinn says. Next month, the IIE and other organizations will hold a twoday workshop in Istanbul, Turkey, aimed at better coordinating efforts and exploring fresh approaches to scaling up access.

The challenge is great - not least because the conflicts seem set to get worse before they get better. "But this must be measured against the costs of not doing it," says Quinn. "If we invest over the next five or ten years in educating and strengthening as many Middle East citizens and children as possible, we will have planted the seeds of a transformed region and much brighter future for the world." -

SUSTAINABLE AID

\section{UN sets out next development goals}

\section{Scientists call for sharper focus in anti-poverty push.}

\section{BY JEFF TOLLEFSON}

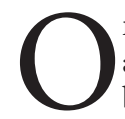
n 25 September, Pope Francis will address the United Nations just before a three-day meeting that will set the agenda for international development efforts over the next 15 years. At the Sustainable Development Summit in New York, global leaders will adopt 17 goals that are meant to improve the lives of the world's poorest people by 2030, without jeopardizing the health of the planet.

Ambitious and broad, these Sustainable Development Goals (SDGs) would, if met, greatly improve human welfare. But some experts fear that the goals are too numerous and vague to have practical value. "I'm a little worried that there are too many of them," says Steven Radelet, director of the Global Human Development Program at Georgetown
University in Washington DC. “They may fall prey to the old adage that if everything is a priority, then nothing is a priority."

First on the list: "End poverty in all its forms everywhere". Second is to end hunger and achieve food security while improving nutrition and promoting sustainable agriculture. The list goes on to address fundamental issues such as education, gender equality and access to water and basic sanitation services. It also calls for economic growth, environmental conservation and clean energy for all people, while urging action to combat climate change. The goals are supplemented by 169 specific targets that are meant to clarify the work that needs to be done.

Under discussion since 2012, the SDGs replace the expiring Millennium Development Goals, which the UN adopted in 2000. Those eight objectives called, among other things, for halving extreme poverty, reducing mortality among children under five by two-thirds and instituting universal primary 